\title{
Local staging of prostate cancer with imaging: can hybrid imaging be the solution?
}

\author{
Baris Turkbey \\ Molecular Imaging Program, National Cancer Institute, National Institutes of Health, Bethesda, MD, USA \\ Correspondence to: Baris Turkbey, MD. 10 Center Drive, Room B3B85, Bethesda, MD 20892, USA. Email: turkbeyi@mail.nih.gov. \\ Provenance and Peer Review: This article is commissioned and reviewed by the Section Editor Dr. Sherif Mehralivand (Molecular Imaging Program, \\ National Cancer Institute, National Institutes of Health, Bethesda, Maryland, USA). \\ Comment on: Muehlematter UJ, Burger IA, Becker AS, et al. Diagnostic accuracy of multiparametric MRI versus 68Ga-PSMA-11 PET/MRI for \\ extracapsular extension and seminal vesicle invasion in patients with prostate cancer. Radiology 2019;293:350-8.
}

Submitted Jan 09, 2020. Accepted for publication Feb 28, 2020.

doi: $10.21037 /$ tau.2020.03.12

View this article at: http://dx.doi.org/10.21037/tau.2020.03.12

Accurate local staging is crucial in clinical management of prostate cancer (1). Currently, multiparametric magnetic resonance (mpMRI) is the most established imaging method for local staging and although this imaging modality offers a high-resolution capability, it is still limited in staging of prostate cancer, mainly for microscopic capsular involvement. Initial studies had focused on a binary approach for prediction of extraprostatic extension (EPE), whereas later studies aimed to utilize some subjective (e.g., capsular bulge, irregularity) (2) and few objective measures (e.g., lesion-capsule contact length) (3). Most recently, few studies have reported development of more objective scoring systems for EPE prediction in prostate cancer patients (4). Despite all efforts, capability of mpMRI in local staging is still limited and not convincing enough to be used routinely.

Targeted imaging with positron emission tomography (PET) tracers such as prostate specific membrane antigen (PSMA) has a documented role in detecting clinically significant prostate cancers and bone and nodal metastases (5); however, its utility for local staging is not widely studied. In this single center retrospective study, Muehlematter et al. aim to compare diagnostic accuracy and inter-reader agreement of mpMRI and PSMA PET/MRI in 40 patients who were diagnosed with intermediate and high-risk prostate cancer at the preoperative phase (6). The authors used a Likert system for independent evaluation of EPE and seminal vesicle invasion (SVI) on mpMRI and PSMA PET/MRI. Their results indicated that mpMRI and
PSMA PET/MRI have similar sensitivities for the detection of EPE and SVI. Only at the region level, specificity of mpMRI was significantly higher than PSMA PET/MRI for EPE and SVI detection. The resultant accuracies were similar for both imaging techniques. Moreover, interreader agreement was moderate for EPE but was low for SVI and similar for both mpMRI and PSMA PET/MRI (Figure 1). The authors conducted an extensive analysis in this retrospective study, however their study population was relatively small, and the cohort included a relatively high proportion of high risk prostate cancer patients, which limits the generalizability of their findings to the larger patient populations in which practicing physicians need to utilize imaging.

One important aspect of this study could have been whether MRI or PSMA PET component contributed EPE and SVI detection in the PET/MRI arm. However, this was not formally studied in this study. Theoretically, PSMA can be helpful to detect subtle SVI where background signal does not overlap with tumor related uptake, whereas its contribution for EPE detection, which is heavily dependent on morphologic features and resultant high in-plane resolution may be limited due to the low spatial resolution nature of PET imaging. In future studies, it may be useful to compare MRI and PSMA PET alone for local staging.

In conclusion, local staging is an important aspect of prostate cancer and reported utility of imaging is still limited for this indication. The study by Muehlematter $e$ t al. is quite encouraging to explore use of targeted molecular 


\section{Diagnostic Accuracy of Multiparametric MRI vs. ${ }^{68} \mathrm{Ga}-\mathrm{PSMA}-11$ PET/MRI for Extracapsular Extension (ECE) and Seminal Vesicle Invasion (SVI) in Patients with Prostate Cancer}

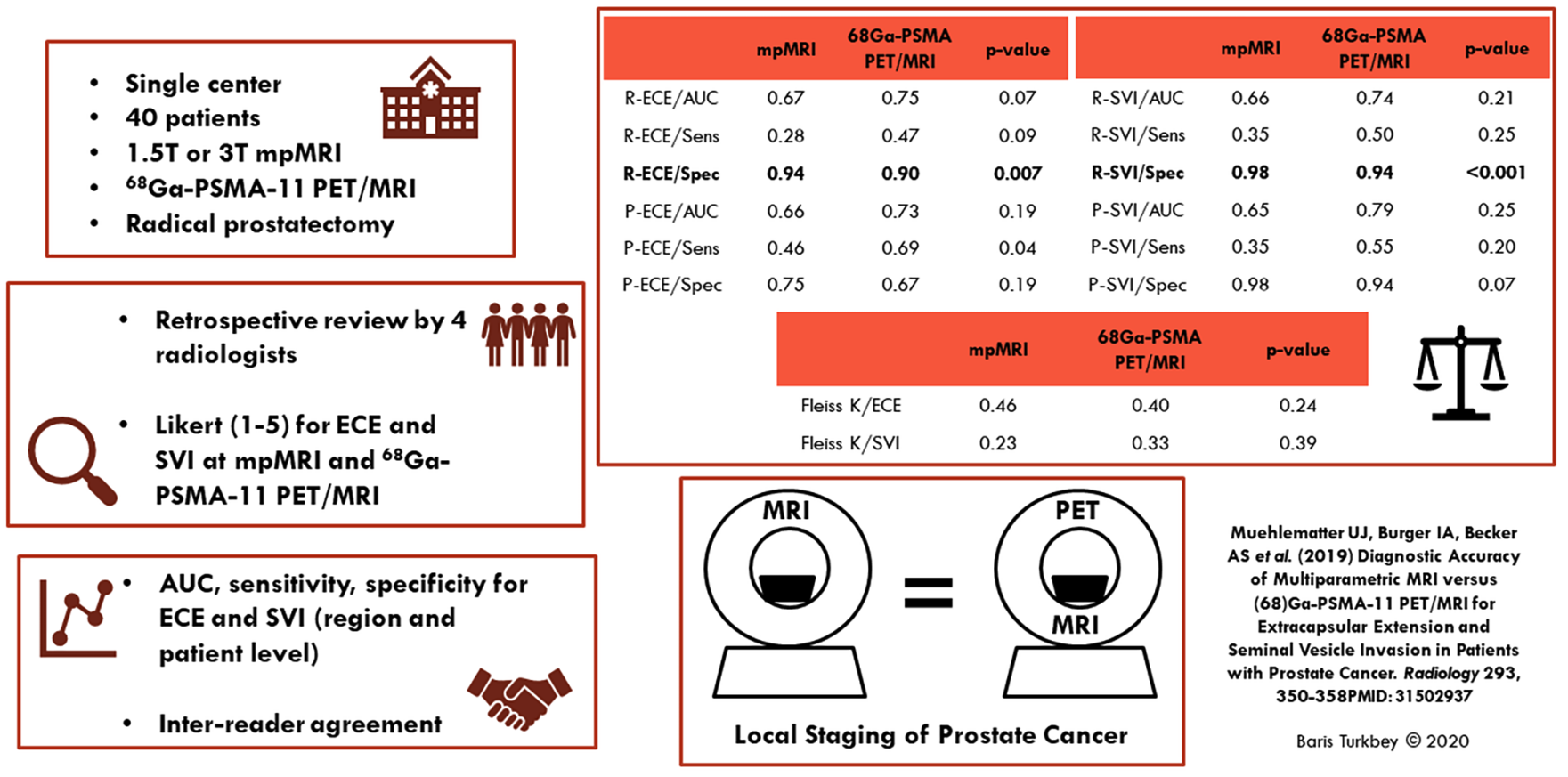

Figure 1 Visual abstract of "Diagnostic accuracy of multiparametric MRI versus ${ }^{68}$ Ga-PSMA-11 PET/MRI for extracapsular extension and seminal vesicle invasion in patients with prostate cancer" (6).

imaging in conjunction with anatomic MRI. As mentioned by the authors, this use of PSMA PET/MRI comes with a cost of lower specificity for local staging of prostate cancer. It will be quite interesting to observe prospective use of hybrid imaging in larger patient populations with more diverse disease risk categories.

\section{Acknowledgments}

Funding: None.

\section{Footnote}

Conflicts of Interest: The author has completed the ICMJE uniform disclosure form (available at http://dx.doi. org/10.21037/tau.2020.03.12). Cooperative research and development agreements with Philips and Nvidia; Royalties from Invivo; Patent for related intellectual property in field of prostate computer-aided diagnosis (National Institutes of Health-owned).

Ethical Statement: The author is accountable for all aspects of the work in ensuring that questions related to the accuracy or integrity of any part of the work are appropriately investigated and resolved.

Open Access Statement: This is an Open Access article distributed in accordance with the Creative Commons Attribution-NonCommercial-NoDerivs 4.0 International License (CC BY-NC-ND 4.0), which permits the noncommercial replication and distribution of the article with the strict proviso that no changes or edits are made and the original work is properly cited (including links to both the formal publication through the relevant DOI and the license). See: https://creativecommons.org/licenses/by-nc$\mathrm{nd} / 4.0 /$.

\section{References}

1. Hull GW, Rabbani F, Abbas F, et al. Cancer control with radical prostatectomy alone in 1,000 consecutive patients. J Urol 2002;167:528-34.

2. Futterer JJ, Heijmink SW, Scheenen TW, et al. Prostate cancer: local staging at 3-T endorectal MR imaging--early 
experience. Radiology 2006;238:184-91.

3. Rosenkrantz AB, Shanbhogue AK, Wang A, et al. Length of capsular contact for diagnosing extraprostatic extension on prostate MRI: Assessment at an optimal threshold. J Magn Reson Imaging 2016;43:990-7.

4. Mehralivand S, Shih JH, Harmon S, et al. A Grading System for the Assessment of Risk of Extraprostatic Extension of Prostate Cancer at Multiparametric MRI. Radiology 2019;290:709-19.

Cite this article as: Turkbey B. Local staging of prostate cancer with imaging: can hybrid imaging be the solution? Transl Androl Urol 2020;9(2):834-836. doi: 10.21037/tau.2020.03.12
5. Hope TA, Afshar-Oromieh A, Eiber M, et al. Imaging Prostate Cancer With Prostate-Specific Membrane Antigen PET/CT and PET/MRI: Current and Future Applications. AJR Am J Roentgenol 2018;211:286-94.

6. Muehlematter UJ, Burger IA, Becker AS, et al. Diagnostic Accuracy of Multiparametric MRI versus (68)Ga-

PSMA-11 PET/MRI for Extracapsular Extension and Seminal Vesicle Invasion in Patients with Prostate Cancer. Radiology 2019;293:350-8. 